\title{
A RESEARCH OF CONSANGUINITY IN JAPANESE YOUNG COUPLES
}

\author{
Yuri Hosoda, Keiko FuJIKI, and Akira NaKaJima \\ Department of Ophthalmology, Juntendo University School of Medicine, \\ Tokyo 113, Japan
}

In the past, the rate of consanguineous marriage in Japanese population was high $(6 \%$ in Hiroshima and Nagasaki, and $4 \%$ in Tokyo) (Schull and Neel, 1965). However, it has decreased rapidly during the last two decades. The nationwide survey (Imaizumi et al., 1975) showed that the mean rate of first cousin marriage was $0.86 \%$ among young couples who got married during June 2, 1967 to June 1, 1972.

In Kanto district, Furusho (1979) reported that the rate of first cousin marriage and inbreeding coefficient were $2.31 \%$ and 0.00211 in Tokyo, and $2.88 \%$ and 0.00263 in Yokohama, respectively. These data were collected from 6,866 school boys in Tokyo and Yokohama, who were born during the period of April 1949 through March 1950.

Imaizumi (1977) reported the mean inbreeding coefficient by Cohort in relation with the year of marriage in two cities. The mean inbreeding coefficients were $0.0062,0.0023$, and 0 in Gyoda city; and $0.0046,0.0040$, and 0.0010 in Hasuda city for the marriage year of $\sim 1945,1946-1961$, and $1962 \sim$, respectively.

The present study is to investigate the rate of consanguineous marriage among young couples who got married during 1972-1981.

The data were collected by questionnaire to 833 persons who are working at pharmaceutical companies in Tokyo and Osaka area, and 150 patients of contact lens clinic at Juntendo University. All of them have married during 1972-1981.

Table 1 shows their residence and place of family register (honseki) and place of birth. The number of consanguineous marriage is shown in round bracket. Table 2 shows the frequency of consanguineous marriage summarized. The rate of first cousin marriage and mean inbreeding coefficient was $0.1 \%$ and 0.00013 , respectively. These values are surprisingly small. It may be due to the fact that the data was collected in large cities.

Nationwide research is strongly needed.

Acknowledgment The authors wish to express much gratitude to the members of Toray industries, Inc., Shionogi \& Co., Ltd. and other companies for their contribution of data to this survey.

Received August 12, 1982 


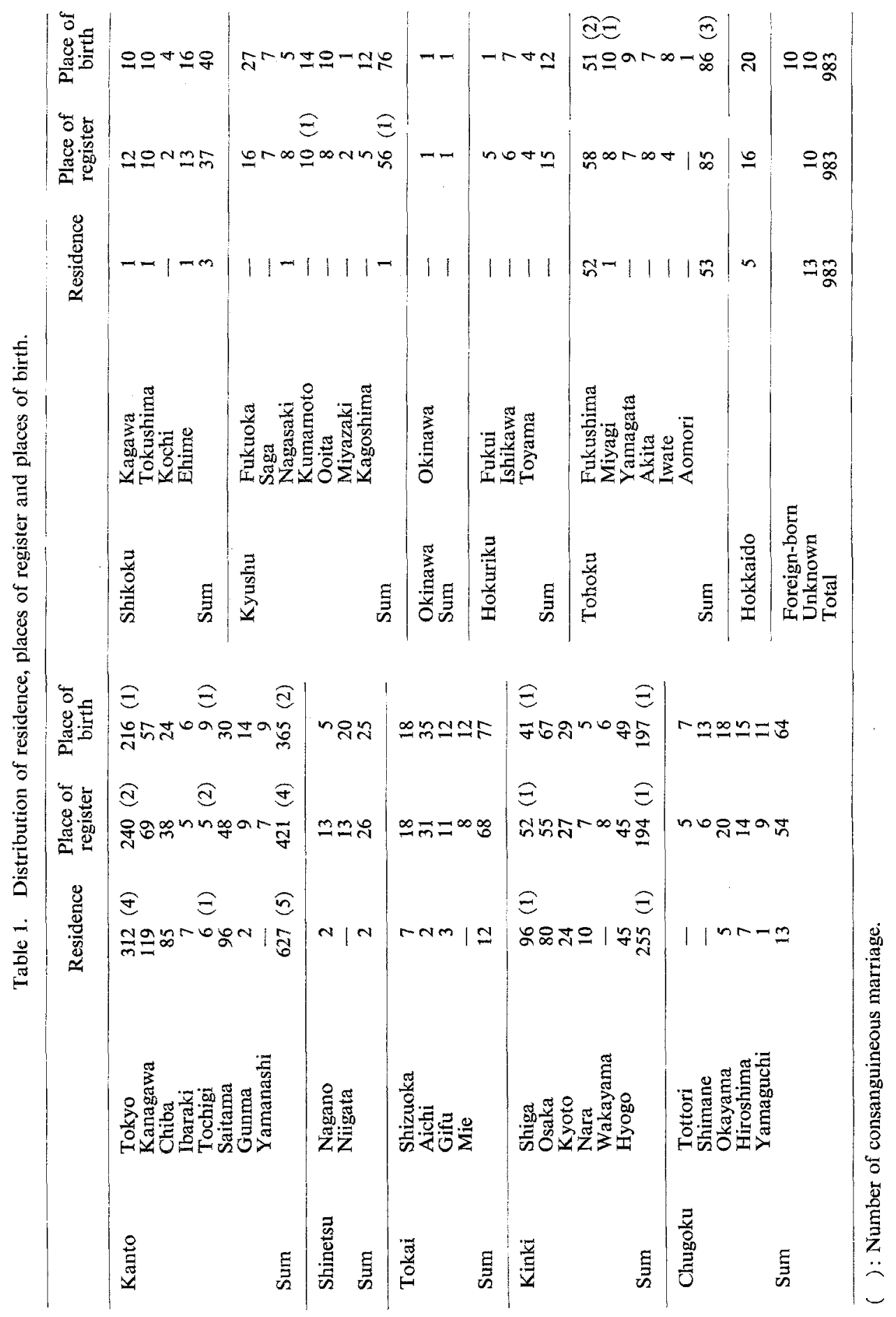


Table 2. Frequency of consanguineous marriage in young couples (married year: 1972-1981).

\begin{tabular}{lcccccccccc}
\hline $\begin{array}{c}\text { Inbreeding } \\
\text { coefficient } \\
\times 128\end{array}$ & 16 & 8 & 4 & 2 & $>0$ & 0 & Total & $\begin{array}{c}1 \mathrm{C} \\
(\%)\end{array}$ & Unknown \\
\hline & - & 1 & 1 & 2 & 2 & 976 & 982 & 0.10 & 1
\end{tabular}

IC, the first cousin marriage.

\section{REFERENCES}

Furusho, T. 1979. Incidence of consanguineous marriages in Tokyo and Yokohama. Jpn. $J$. Human Genet. 24: 293-294.

Imaizumi, Y., Shinozaki, N., and Aoki, H. 1975. Inbreeding in Japan: Results of a nation-wide study. Jpn. J. Human Genet. 20: 91-107.

Imaizumi, Y. 1977. A demographic approach to population structure in Gyoda and Hasuda, Japan. Hum. Hered. 27: 314-327.

Schull, W.J., and Neel, J.V. 1965. The Effects of Inbreeding on Japanese Children. Harper and Row, New York, pp. 11-30. 